\title{
The Rising Number of COVID-19 Cases Reflecting Growing Search Trend and Concern of People: A Google Trend Analysis of Eight Major Countries
}

\author{
Manik Sharma $^{1}$ (D) Samriti Sharma ${ }^{2}$ \\ Received: 6 May 2020 / Accepted: 11 May 2020/Published online: 20 May 2020 \\ (C) Springer Science+Business Media, LLC, part of Springer Nature 2020
}

The Corona-virus (2019-nCoV) is a kind of zoonotic virus that has been first proclaimed in Wuhan (China). By 10th April 2020, the pandemic (COVID-19) has infected more than one and a half million (1698881) people across the world. During the last couple of weeks a sharp surging trend (COVID-19 infection) has been recorded [1]. The community dissemination is a major cause behind this exponential growth. The substantial growth of this pandemic virus (COVID-19) has created a scary and stressful environment [2]. The consequence of the stress is so high that fear of infection forces the persons to suicide [3]. The key intention of this analysis is to highlight the escalating cases of COVID-19 and its refection in the growing search trend and concern of the people from 01st March to 10th April 2020.

During this observation period, the worldwide COVID-19 infected cases have been raised from 88,585 to $1,698,881$ ( $\sim 1.7$ million). The highest number of new cases (101736) have been observed on 3rd April. An average growth rate of $7.58 \%$ (new_cases $>70,000$ ) has been witnessed. As of 10th March, the growth in the global contaminated cases has been intensified. Moreover, in the last five days of this study, 349,830 new cases have been appended. Likewise, the mortality rate has also skyrocketed over this time, which is badly affecting the mental state and immunity of the humans.

Similar statistics of eight major countries (United States, Spain, Italy, France, United Kingdom, China, Iran, and India) have also been accessed (Table 1).

This article is part of the Topical Collection on Systems-Level Quality Improvement

Manik Sharma

manik_sharma25@yahoo.com

1 Department of CSA, DAV University, Jalandhar, India

2 Department of CS, GNDU, Amritsar, India
Among these countries, an unexpected growth has been witnessed in both infected and fatal cases. The impacts of COVID-19 are on the peak for United States, Spain, Italy and France. Due to the momentous population density, Indians are frightened of mass destruction [4]. .

Additionally, the COVID-19 fear and concern have been well reflected on Google searches and the same can be validated through Google wave of interest. The Google trend of these eight countries for the term 'COVID-19' has also been explored. The trend value reflects the people's interest in the searched item. The highest and lowest rates of search interest on the Google wave are represented by 100 and 0 respectively (Fig. 1).

The waves of the Google interest have been raised over the observed period (01st March to 10th April). The increased Google trend implicitly represents the folk's state of distress, despair, and concern for this pandemic. A sharp increase in the trend has been observed from 10th march to 10th April 2020. During the observation period, a series of high values could be observed on the Google wave of interest of United States, Spain, Italy, France, United Kingdom, China, Iran, and India. For United States, 23rd and 27th March 2020 represents the peaked searches on the Google wave of interest. The average value of the Google interest for two different phases i.e.(01st January to 29th February) and (01st March to 10th April) have also been computed. The mean values for first and second phase of United States, Spain, Italy, France, United Kingdom, China, Iran and India are $(0.78, \mathbf{6 6 . 4 6}),(0.81, \mathbf{6 0 . 8 5}),(1.65, \mathbf{5 6 . 6 8}),(1.15$, 52.78), (1.03, 59.41), (9.86, 44.29), (1.28, 23.19) and $(0.04,39.78)$ respectively. Additionally, the correlation rate between the total COVID-19 contaminated cases of countries (United States, Spain, Italy, France, United Kingdom, China, Iran and India) and their corresponding Google trend values are $(0.37,0.58,0.52,0.28$, 
Table 1 Statistics of COVID-19 [1]

\begin{tabular}{lllcrc}
\hline \multirow{2}{*}{ Country } & \multicolumn{2}{l}{ Number of Infected Cases } & & \multicolumn{2}{c}{ Number of Fatalities } \\
\cline { 2 - 3 } \cline { 5 - 6 } & On 01st March 2020 & On 10th April 2020 & & On 01st March 2020 & On 10th April 2020 \\
\hline United States & 75 & 502,876 & 158,273 & 01 & 18,747 \\
Spain & 84 & 147,577 & 00 & 16,081 \\
Italy & 1701 & 124,869 & 41 & 18,849 \\
France & 130 & 73,758 & 02 & 8958 \\
United Kingdom & 36 & 81,953 & 00 & 3339 \\
China & 80,026 & 68,192 & 2912 & 4232 \\
Iran & 978 & 7600 & 54 & 249 \\
India & 03 & & 00 & 423 \\
\hline
\end{tabular}
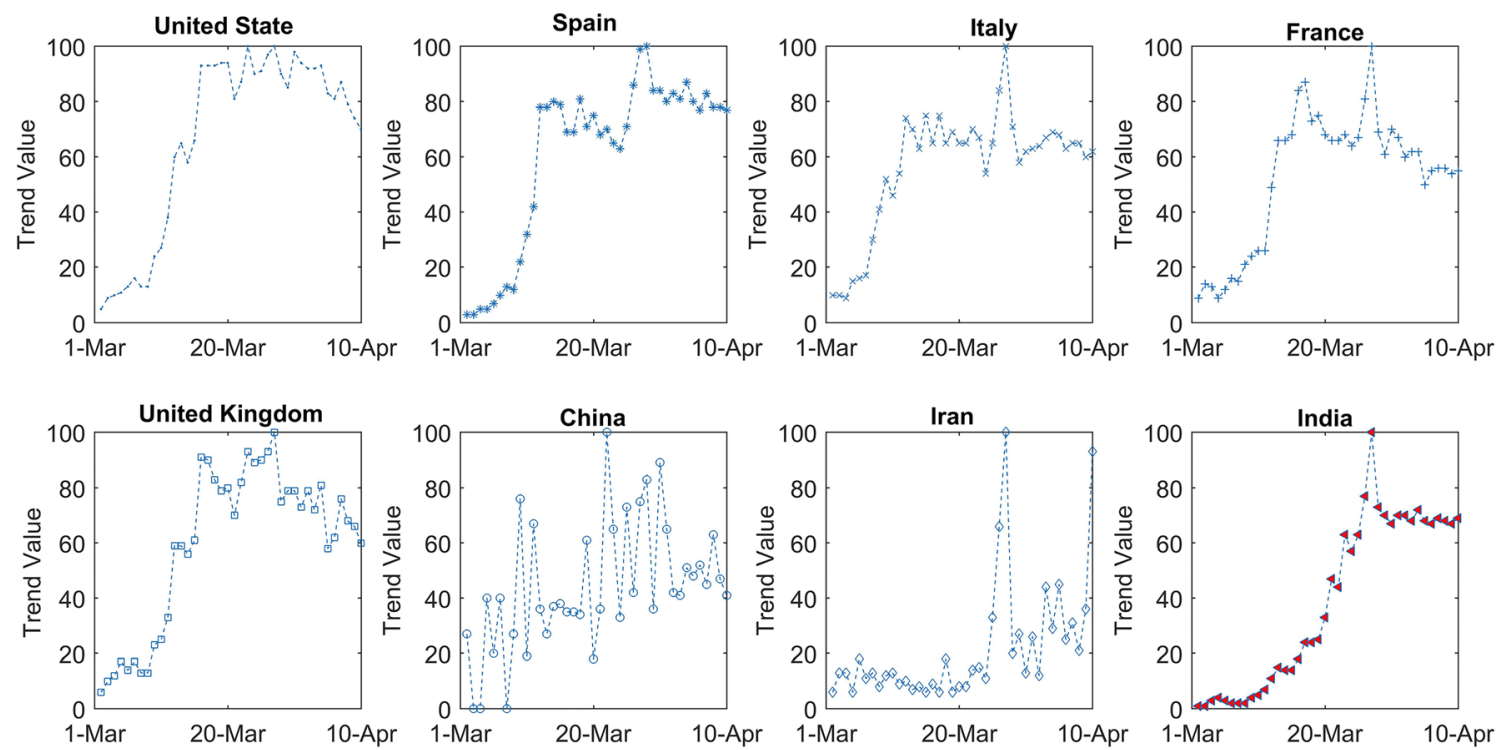

Fig. 1 Google Trend (COVID-19)

$0.26,0.49,0.60$ and 0.61$)$ respectively. A positive correlation between the number of infected cases and the Google trend values have been recorded for eight major countries. The correlation value is higher for Spain, Iran and India.

The Google trend can be further mined to determine the least and most infected regions of the countries. To avoid the massive increase of psychological disorders, there is a need to access the mental state of COVID19 afflicted individuals [5]. Based upon the high wave of interest in the regions, the semantic analysis of the searches can be carried out to find the prevalence of psychological impacts and the need of psychological intervention (behaviour and cognitive) for mental health problems during and after this pandemic. This would help in delivering therapeutic assistance to improve psychological resilience and to boost immunity of the COVID afflicted, suspected and infected victims [6].

\section{Compliance with Ethical Standards}

Conflict of Interest None.

\section{References}

1. COVID-19 coronavirus pandemic. https://www.worldometers.info/ coronavirus/ (accessed 15.04.2020), 2020.

2. Gautam, Ritu, and Manik Sharma. "2019-nCoV pandemic: A disruptive and stressful atmosphere for Indian academic fraternity." Brain, Behavior, and Immunity (2020).

3. Sahoo, Swapnajeet, et al. "Self-harm and COVID-19 Pandemic: An emerging concern-A report of 2 cases from India." Asian journal of psychiatry (2020). (DOI: https://doi.org/10.1016/j.ajp.2020. 102104).

4. Sharma, Samriti, Manik Sharma, and Gurvinder Singh. "A chaotic and stressed environment for 2019-nCoV suspected, infected and 
other people in India: fear of mass destruction and causality." Asian Journal of Psychiatry 51 (2020): 102049.

5. Zhang, Jie, et al., The differential psychological distress of populations affected by the COVID-19 pandemic. Brain, Behavior, and Immunity, 2020.
6. Kim, Sung-Wan, and Kuan-Pin Su., Using psychoneuroimmunity against COVID-19. Brain, Behavior, and Immunity, 2020.

Publisher's Note Springer Nature remains neutral with regard to jurisdictional claims in published maps and institutional affiliations. 